\title{
Tsafon
}

Revue d'études juives du Nord

$74 \mid 2017$

La Déclaration Balfour, vers l'État d'Israël ?

\section{Cyril Grange, Une élite parisienne. Les familles de la grande bourgeoisie juive (1870-1939)}

Danielle Delmaire

\section{(2) OpenEdition}

Édition électronique

URL : https://journals.openedition.org/tsafon/433

DOI : $10.4000 /$ tsafon.433

ISSN : 2609-6420

Éditeur

Association Jean-Marie Delmaire

Édition imprimée

Date de publication : 1 décembre 2017

Pagination : 167-170

ISSN : 1149-6630

\section{Référence électronique}

Danielle Delmaire, «Cyril Grange, Une élite parisienne. Les familles de la grande bourgeoisie juive (18701939)», Tsafon [En ligne], 74 | 2017, mis en ligne le 31 mai 2018, consulté le 24 juin 2021. URL : http:// journals.openedition.org/tsafon/433 ; DOI : https://doi.org/10.4000/tsafon.433

Ce document a été généré automatiquement le 24 juin 2021.

Tsafon. Revues d'études juives du Nord 


\title{
Cyril Grange, Une élite parisienne. Les familles de la grande bourgeoisie juive (1870-1939)
}

\author{
Danielle Delmaire
}

\section{RÉFÉRENCE}

Cyril Grange, Une élite parisienne. Les familles de la grande bourgeoisie juive (1870-1939),

Paris, CNRS éditions, déc. 2015, 547 p., $27 €$.

1 Dans une collection des éditions du CNRS, dirigée par l'historienne Esther Benbassa, l'auteur publie un énorme volume issu d'une recherche universitaire. Il s'est spécialisé dans l'étude des élites de la société française aux $\mathrm{XIX}^{\mathrm{e}}$ et $\mathrm{XX}^{\mathrm{e}}$ siècles et, dans ce milieu, il a trouvé des familles juives qu'il nous présente, ici, avec abondance de détails.

2 Les bornes sociales et chronologiques de l'étude restent difficiles à définir. En effet, à partir de quels critères une famille appartient-elle à l'élite sociale ? Par la fortune, le style de vie, les lieux de rencontre, les largesses philanthropiques...? L'auteur s'en tient, sans doute avec pertinence, aux annuaires mondains qui, d'ailleurs, ne listent pas toujours selon les mêmes critères. Quant aux bornes chronologiques, l'auteur choisit deux années cruciales dans les guerres franco-allemandes : 1870 c'est-à-dire la défaite française devant la Prusse dont plusieurs familles juives étaient originaires et 1940 c'est-à-dire la défaite française, encore, face à l'invasion par l'Allemagne nazie dont les familles juives ont tant à craindre même si elles n'en pas une conscience bien nette.

3 Les sources utilisées sont abondantes. Outre les dossiers de fonds d'archives bien connus comme les Archives nationales et autres fonds publics, l'auteur n'a pas mis de limites à sa curiosité : il a fouillé dans des archives privées de grandes familles (Rothschild, Fould et tant d'autres), il a aussi utilisé les sources très riches, pour une telle étude, de l'état civil, les registres de mariages religieux et notamment ceux de la prestigieuse synagogue de la rue de la Victoire qui venait d'être édifiée, les annuaires 
mondains et ceux de diverses associations, les dossiers de naturalisations car les fondateurs de dynastie sont souvent issus de l'immigration etc. Il semble bien qu'il ait visité tous les fonds utilisables pour sa recherche. Bien que les noms soient notoirement connus pour être ceux de familles juives, l'auteur reconnait avoir eu recours à l'onomastique, critère «inévitablement imparfait » reconnaît-il (pp. 49 et $359)^{2}$.

4 Fort logiquement, l'auteur commence par présenter ces familles, au moins les plus riches: Rothschild, Fould, Halphen, Orly Worms de Romilly, Camondo, Rodrigues Gradis..., il est vain de tenter de toutes les citer dans le cadre de cette recension. La plupart d'entre elles se sont établies à Paris à la faveur de l'émancipation accordée aux juifs par l'Assemblée constituante. Quelques-unes ont même établi domicile à Paris dès les années 1780. Elles sont, en partie, responsables du développement rapide de la communauté juive parisienne. La plupart de ces familles, sauf celles originaires du sudouest de la France, viennent de l'Europe centrale (Rothschild en est le parfait exemple) voire de la Russie (Gunzburg, Ephrussi) mais d'autres ont quitté l'Empire ottoman comme les Camondo. À partir d'un ou deux personnages, voire une fratrie, une dynastie se met en place durant le XIX ${ }^{e}$ siècle. Les alliances matrimoniales contribuent à agrandir cette élite mondaine. La généalogie, science auxiliaire incontournable de l'histoire, montre clairement l'élargissement de la place de ces familles de la bourgeoisie juive dans la société française, au moins à Paris.

5 Les fortunes sont de diverses origines. La banque et les finances participent largement à la réussite des chefs de famille, ces activités ne sont jamais que le prolongement de cette activité très longtemps dévolue, car imposée, aux juifs que furent le prêt et le change dans les villes qui se développent. Le négoce est lui aussi source des fortunes juives parisiennes et se trouve souvent associé aux affaires bancaires. Il en est de même pour l'industrie. Les Worms, les Pereire, les Rothschild sont à la tête de maisons bancaires mais investissent aussi dans la construction des chemins de fer et autres activités industrielles, voire pétrolières et automobiles pour les Deutsch de la Meurthe au début $\mathrm{du} \mathrm{xx}^{\mathrm{e}}$ siècle. Une ou deux générations passent et les activités se diversifient pour sortir des affaires (affaires qui n'enrichissent pas que les familles juives d'ailleurs au XIXe siècle, bien des chrétiens, catholiques ou protestants, suivent ce même parcours, l'auteur n'insistent pas assez, me semble-t-il, sur la banalité de tels parcours chez les familles bourgeoises quelle que soit leur appartenance religieuse). Tandis que les pionniers se sont formés sur le tas et ont transmis leur savoir-faire à leurs enfants (début et milieu du XIX ${ }^{e}$ siècle), quelques petits-fils fréquentent les universités et les grandes écoles comme Polytechnique, Centrale et deviennent ingénieurs, médecins, avocats voire artistes comme le musicien Fernand Halphen ${ }^{3}$ et érudits littéraires comme les frères Reinach (fin XIX ${ }^{e}$ siècle).

6 La richesse de ces familles se mesure au patrimoine mobilier (actions et obligations dans de nombreuses entreprises) et immobilier (appartements luxueux à Paris, châteaux et résidences dans les campagnes ou dans les régions de villégiature nouvelle comme les côtes normandes), voire des biens ruraux tels les vignobles dans le Bordelais notamment. Quelques membres de ces familles, à partir du début du $\mathrm{xx}^{\mathrm{e}}$ siècle, s'intéressent au sort de leurs coreligionnaires et investissent dans des entreprises de bienfaisance en Europe voire dans le Nouveau Monde et même en Palestine. L'auteur minimise cette part de philanthropie car trop peu de lignes (deux petits paragraphes à la page 420) sont consacrées au solide soutien financier qu'Edmond de Rothschild 
accorda aux implantations pionnières juives en Palestine dès la fin du XIX siècle, alors qu'actuellement encore le souvenir du Bienfaiteur reste vivace en Israël. De même des dons au Fonds national juif (Keren Kayemeth LeIsraël) sont oubliés, même si cette bourgeoisie juive, très patriote, se méfie du sionisme, elle participe quand même, parfois, à l'aide accordée à leurs coreligionnaires peu fortunés. Certains s'impliquent et aident financièrement les établissements scolaires de l'Alliance israélite universelle, autre forme de philanthropie caractéristique de la bourgeoisie en général et non particulièrement de la bourgeoisie juive (il faut le souligner: cette forme de bienfaisance est aussi un critère d'intégration dans la société où évoluent ces familles). Les dames (comme les dames patronnesses catholiques) accordent leur temps et une partie de leur fortune aux pauvres en favorisant l'implantation de dispensaires et d'hôpitaux (Hôpital Rothschild). L'aisance financière permet aussi aux dames de tenir un salon littéraire ou musical (Flore Singer) et c'est un peu le monde proustien que l'on retrouve dans ce milieu. Le mécénat artistique est plutôt l'affaire des hommes. Le mécène le plus connu est encore Moïse de Camondo mais un Kahnweiler n'est pas en reste, lui qui aida bien des peintres à émerger.

7 Par une recherche très fouillée dans les registres de mariage des synagogues, et plus précisément de la synagogue de La Victoire qui reçoit le gratin de la communauté juive, l'auteur a pu mettre en évidence une forte endogamie durant le XIX ${ }^{e}$ siècle qui se réduit au fur et à mesure de l'avancée dans les décennies du siècle suivant. Les mariages mixtes, rares au milieu du $\mathrm{XIX}^{\mathrm{e}}$ siècle, deviennent plus courants au $\mathrm{xx}^{\mathrm{e}}$ siècle. De mieux en mieux intégrés dans leur milieu, les membres juifs de la haute société parisienne finissent par trouver leur partenaire non juif dans ce même cercle social. Dans la quasi majorité des cas, une telle union aboutit à une conversion au christianisme (souvent catholicisme, parfois protestantisme), ce qui n'empêche pas de somptueux mariages dans les églises huppées de la capitale. Des arrangements financiers, même avec la noblesse, sont parfois à l'origine de ces unions. Avec minutie l'auteur énonce toutes les possibilités de renoncement au judaïsme et d'acceptation par le Vatican de telles unions. Toutefois, les conversions, dans ce milieu de l'élite bourgeoise juive, ne sont pas dues uniquement à un mariage, des enfants de bonne famille juive entrent dans le catholicisme (plus minoritairement dans le protestantisme) par conviction, tels les frères Ratisbonne qui ont fondé la congrégation de Notre-Dame de Sion.

Qu'advient-il de ces couples: quand se marient-ils? Les mois des fêtes juives sont évités, les jours préférés pour la cérémonie religieuse sont les jeudis ou les dimanches. Quel est l'âge au premier mariage ? Quelle est la fréquence des naissances ? À toutes ces questions l'auteur apporte des réponses d'ordre démographique et sociologique souvent très précises. Il examine aussi les contrats de mariage pour évaluer les apports patrimoniaux des partenaires et aussi pour déceler les réseaux matrimoniaux qui consolident les familles et les fortunes. On peut toutefois regretter, dans ces chapitres, la présence de tableaux et de croquis complexes, compréhensibles uniquement pour les spécialistes de ces disciplines.

Malgré les mariages mixtes, une grande fidélité à la religion des pères caractérise certaines familles qui s'investissent dans la gestion de la communauté juive de Paris et dans ses œuvres caritatives ou éducatives. À ce sujet, l'implication du grand rabbin Zadoc Kahn, dans les dernières décennies du XIX ${ }^{e}$ siècle, dans l'enseignement religieux aurait pu être souligné avec plus de force. La famille Rothschild fournit l'exemple le plus probant de cette fidélité au judaïsme et l'engagement pour défendre la cause des 
juifs en France et même au-delà. Avec justesse, l'auteur cite même des cas de résistance au prosélytisme chrétien telle Flore Singer, née Ratisbonne, qui refuse sa conversion et préfère rompre ses fiançailles avec Alphonse Ratisbonne converti.

Cet ouvrage volumineux fait pénétrer le lecteur dans le monde de Gilberte Swann dont se demande l'auteur s'il est fiction ou réalité (p. 284). Il possède, indubitablement, les qualités d'une recherche universitaire, l'auteur ne lésine pas sur détails précis, dûment justifiés, et a mené des fouilles sérieuses dans de nombreux fonds d'archives. Mais la publication était-elle destinée aux spécialistes, auquel cas elle est une réussite, ou à un public plus large? Dans ce cas, elle est parfois déroutante : le lecteur se perd dans des croquis, plans et tableaux manifestement destinés aux érudits de certaines disciplines, il se perd encore dans des explications annexes comme la position du Vatican sur les possibilités de mariages mixtes. Tout cela aurait pu être synthétisé me semble-t-il. L'on peut aussi regretter certaines redites sur l'onomastique, la fidélité au judaïsme, les relations matrimoniales etc. Le plan aurait pu être plus resserré autour de thèmes fédérateurs lorsque les arguments se recoupaient d'un chapitre à l'autre. Enfin malgré l'épaisseur de l'ouvrage, mais qui aurait pu être réduite, on peut aussi regretter de rares oublis ou des développements trop courts comme la position des familles de la grande bourgeoisie juive à l'égard du sionisme : sa pensée, ses représentants (Bernard Lazare et André Spire sionistes convaincus côtoyaient ces milieux, et le grand rabbin Zadoc Kahn n'était pas indifférent à ce nouveau courant au sein des communautés juives), son soutien aux premiers pionniers en Palestine, ou au contraire son refus catégorique de l'émergence d'un nationalisme juif qui s'érige en opposition à l'amour de la France. De même des comparaisons, succinctes par quelques allusions, avec la bourgeoisie juive de province, certes moins huppée qu'à Paris, auraient enrichi l'étude. En province aussi, les familles les plus riches se sont implantées dans les villes à la faveur du développement économique des régions, elles se sont investies financièrement dans le commerce, les enfants ont gravi les échelons de la société grâce à des études, les mariages endogames puis exogames touchent ces communautés etc.

11 Bref, il aurait donc fallu affirmer avec plus de force que ces familles de la grande bourgeoisie juive partagent avec les familles de la bourgeoisie non juive des attitudes caritatives, des convictions sociales car ces familles sont bourgeoises et se comportent comme de nombreuses familles bourgeoises mais elles sont aussi juives et n'oublient pas les valeurs de leur religion. Cette double appartenance est le nœud central d'une telle histoire de ce groupe social.

\section{NOTES}

2. Voir mes remarques sur l'usage de l'onomastique dans la recherche en histoire, à propos du livre de Claire Zalc, Dénaturalisés. Les retraits de nationalité sous Vichy, Paris, Seuil, 2016, dans Tsafon, $n^{\circ} 73$, printemps-été 2017, pp. 187-188.

3. Je renvoie à l'étude de Laure Schnapper, «Fernand Halphen, chef de musique du $13^{\mathrm{e}}$ Régiment d'Infanterie Territoriale, un israélite dans la Grande Guerre », Tsafon, n 68, aut. 2014 - hiver 2015, pp. 15-39. 